\title{
Pengenalan Flora Fauna Melalui Jelajah dan Bermain pada Anak-Anak di Sekitar Taman Keanekaragaman Hayati Batu Putu Lampung
}

\author{
Yeni Rahayu $^{1 *}$, Yanti Ariyanti ${ }^{1}$, Faradila Mei Jayani ${ }^{1}$ dan Hendry Wijayanti ${ }^{1}$ \\ ${ }^{1}$ Program Studi Biologi, Institut Teknologi Sumatera, Jalan Terusan Ryacudu, Way Hui, Jati Agung, \\ Lampung Selatan, Indonesia, 35365 \\ Email*: yeni.rahayu@bi.itera.ac.id
}

\begin{abstract}
Abstrak
Dalam upaya mengembangkan kawasan wisata berbasis edu-ekowisata di Desa Batu Putu, pendidikan masyarakat yang tinggal di sekitar pariwisata, baik dewasa maupun anak-anak, perlu ditingkatkan. Jumlah penduduk dengan kisaran usia anak-anak di sekitar Taman Keanekaragaman Hayati Batu Putu cukup besar. Namun, sumber daya yang dapat memperkenalkan flora dan fauna lokal kepada anak-anak, dan menanamkan karakter kepedulian terhadap keanekaragaman hayati dan lingkungan sangat jarang. Peningkatan pengetahuan tentang flora dan fauna untuk anak-anak yang tinggal di dekat Taman Keanekaragaman Hayati Batu Putu telah dilakukan dengan menggunakan metode yang menyenangkan, yaitu eksplorasi, bercerita dan bermain puzzle. Kegiatan ini bertujuan untuk memperkenalkan flora dan fauna kepada anak-anak dan menjelaskan betapa pentingnya melindungi lingkungan sebagai habitat flora dan fauna. Hasilnya menunjukkan bahwa ada peningkatan pengetahuan anak-anak tentang flora dan fauna. Anak-anak dapat mengenali flora dan fauna lokal yang unik, dan menumbuhkan rasa cinta terhadap flora dan fauna di sekitar mereka. Pengamatan menunjukkan karakter anak-anak yang peduli dengan flora-fauna dan lingkungan mereka telah muncul dari perilaku sehari-hari mereka ketika bermain di sekitar taman. Kegiatan-kegiatan ini mampu mengembangkan kesadaran anak sejak dini untuk melindungi lingkungan di Taman Keanekaragaman Hayati Batu Putu.
\end{abstract}

Kata kunci: desa batu putu, flora-fauna, keanekaragaman hayati, pendidikan lingkungan, wisata edukasi.

\begin{abstract}
In an effort to develop a tourism area based on edu-ecotourism in Batu Putu Village, the education of the community who lived around the tourism, both adults and children, needs to be improved. The number of residents with a range age of children around the Batu Putu Biodiversity Park is quite large. However, people who can introduce the local flora and fauna to children, and instill the character of caring of the biodiversity and the environment are very rare. Increasing knowledge about flora and fauna for children who lived nearby The Batu Putu Biodiversity Park has done using fun methods, namely exploration, telling stories, and playing puzzles. These activities aimed to introduce flora and fauna to children and explain how the importance of protecting the environment as a habitat of the flora and fauna. The results showed that children's knowledge about the flora and fauna were increased. Children were able to recognize the unique local flora and fauna, and grew a sense of love for the flora and fauna around them. The observations showed the children's character that cares about the flora-fauna and their environment has emerged from their daily behavior when playing around the park. These activities developed awareness early on to protect the environment of The Batu Putu Biodiversity Park.
\end{abstract}

Keywords: batu putu village, biodiversity, environmental education, education tourism, flora-fauna 
Format Sitasi: Rahayu, Y., Ariyanti, Y., Jayani, F. M. \& Wijayanti, H. (2020). Pengenalan Flora Fauna Melalui Jelajah dan Bermain pada Anak-Anak di Sekitar Taman Keanekaragaman Hayati Batu Putu Lampung. Jurnal SOLMA, 09(1), 239-248. Doi: http://dx.doi.org/10.29405/solma.v9i1.4894

Diterima: 11 April 2020 | Revisi: 04 Mei 2020 | Dipublikasikan: 30 April 2020

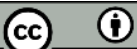

(C) 2020 Oleh authors. Lisensi Jurnal Solma, LPPM-Uhamka, Jakarta. Artikel ini bersifat open access yang didistribusikan di bawah syarat dan ketentuan Creative Commons Attribution (CC BY) license. (http://creativecommons.org/licenses/by/4.0/).

\section{PENDAHULUAN}

Taman Keanekaragaman Hayati Batu Putu merupakan sebuah kawasan yang tengah dicanangkan oleh pemerintah kota Bandar Lampung menjadi kawasan wisata berbasis pendidikan alam. Pada lahan seluas $\pm 2 \mathrm{Ha}$ di kawasan ini akan dibangun pusat wisata edukasi bambu yang mengoleksi ragam jenis bambu nusantara, khususnya Sumatera, dan dunia serta jenis-jenis pohon langka lainnya (Pemerintah Kota Bandar Lampung, 2019). Kawasan ini mempunyai letak strategis, termasuk dalam wilayah administrasi Kota Bandar Lampung dan dapat ditempuh kurang dari 30 menit dari pusat kota. Kemudahan akses mencapai lokasi, kondisi jalan baik dan penduduk setempat yang ramah menjadi potensi kawasan ini sebagai salah satu alternatif pilihan ruang praktik lapangan bagi siswa dan mahasiswa, maupun peneliti.

Dalam upaya pembangunan kawasan wisata, kualitas sumber daya masyarakat (SDM) di sekitar lokasi wisata adalah hal utama yang harus dibangun. Kesiapan SDM perlu menjadi perhatian dan fokus pencapaian pembangunan kawasan wisata, agar dapat mendukung alam dan produk wisata (Sulartiningrum \& Nofiyanti, 2018). Masyarakat yang sejahtera dan terdidik merupakan potensi bagi kawasan wisata berkelanjutan. Pendidikan masyarakat sekitar wisata bukan hanya ditujukan bagi kelompok dewasa, melainkan juga kelompok anak-anak sebagai generasi yang akan mewarisi dan mengelola kawasan tersebut beberapa tahun mendatang. Penanaman karakter pada anak-anak guna membentuk masyarakat yang kenal flora-fauna dan peduli terhadap lingkungannya perlu dimulai sedari dini. Seseorang anak yang memiliki karakter peduli terhadap lingkungan akan berdampak positif bagi kelangsungan hidup lingkungan di sekitarnya (Jayawardana, 2016). Oleh karena itu, mempersiapkan potensi anak-anak di sekitar taman keanekaragaman hayati sebagai generasi yang kelak turut melindungi kawasan adalah kebutuhan mendesak.

Masyarakat desa Batu Putu yang bermukim dekat dengan kawasan taman kehati masih memiliki permasalahan berkaitan dengan SDM dan pengenalan potensi hayati di 
dalam kawasan. Pemerintah daerah melalui dinas pariwisata dan BUMN yang menjadi mitra pemerintah telah melakukan upaya-upaya meningkatkan kualitas SDM, terutama target golongan masyarakat pemuda dan dewasa. Pendidikan lingkungan bagi anak menjadi permasalahan yang luput dari perhatian para pihak selama ini. Tim pengabdian masyarakat Institut Teknologi Sumatera menjawab tantangan itu dengan mengadakan kegiatan pengabdian yang bertujuan, sebagai berikut: 1). Mengenalkan flora-fauna lokal dan fungsi ekologisnya pada anak-anak dengan cara yang menyenangkan; dan 2). Meningkatkan pemahaman tentang pelestarian flora-fauna dan lingkungan pada anak-anak di sekitar Taman Keanekaragaman Hayati Batu Putu, Teluk Betung Barat, Lampung.

\section{MASALAH}

Persoalan yang ditemukan dari hasil observasi tim pengabdian pada masyarakat mitra adalah:

1. Jumlah warga dengan rentang usia anak di sekitar Taman Keanekaragaman Hayati Batu Putu cukup besar, tetapi belum menjadi prioritas edukasi dalam rangka mempersiapkan SDM desa menjadi kawasan wisata berbasis pendidikan alam.

Kegiatan pengabdian ini menargetkan untuk mengedukasi anak-anak dari masyarakat yang bermukim di sekitar Taman Keanekaragaman Hayati Batu Putu.

2. Anak-anak di sekitar Taman Keanekaragaman Hayati Batu Putu terbiasa menjadikan kawasan ini sebagai ruang bermain, bahkan tanpa pengawasan langsung orang tua. Hal ini dapat menjadi potensi dan sekaligus bumerang yang mengancam keberlanjutan kawasan wisata edukasi alam.

Melalui edukasi yang diberikan kepada anak, diharapkan dapat mengarahkan potensi anak sebagai duta pariwisata masa depan, yang turut menjaga kelestarian lingkungan di Taman Keanekaragaman Hayati Batu Putu.

3. Minimnya SDM di desa yang mampu mengenalkan flora-fauna lokal pada anak-anak, serta menanamkan karakter peduli kelestarian hayati dan lingkungan.

Kegiatan yang dilakukan oleh tim pelaksana pengabdian memiliki target utama untuk mengenalkan flora-fauna kepada anak-anak, sehingga ada peningkatan pemahaman anak terhadap pentingnya melestarikan flora-fauna dan lingkungan di sekitar mereka. 


\section{METODE PELAKSANAAN}

Kegiatan pengabdian dilaksanakan dengan metode pembelajaran anak yang menyenangkan, yaitu melalui aktivitas jelajah kawasan, bercerita dan bermain puzzle. Peserta kegiatan adalah anak-anak usia 5 - 10 tahun, yang bertempat tinggal di desa Batu Putu (pemukiman masyarakat yang bersebelahan dengan kawasan taman kehati). Anakanak tersebut merupakan siswa sekolah dasar, maupun pra-sekolah yang dalam keseharian mereka terbiasa menghabiskan waktu bermain bersama di taman kehati. Durasi kegiatan selama 6 bulan, yaitu bulan September 2019 hingga Februari 2020. Tahapan kegiatan terbagi ke dalam 3 tahap: a). tahap pembelajaran; b). tahap observasi pemahaman anak; dan c). tahap evaluasi.

a. Tahap Pembelajaran dengan Metode Jelajah

Tahap ini dilaksanakan selama 2 hari pada bulan pertama, yaitu tanggal $13-14$ September 2019. Lokasi kegiatan adalah jalur setapak di dalam Taman Keanekaragaman Hayati Batu Putu sampai area air terjun. Materi pembelajaran disampaikan oleh narasumber (tim pelaksana pengabdian) dalam kelompok kecil di lapangan. Anak-anak diajak untuk berjalan menjelajahi kawasan taman kehati selama 3-4 jam per hari, sembari mengamati flora dan fauna yang dijumpai sepanjang penjelajahan. Waktu penjelajahan adalah waktu bermain anak sehari-hari, yaitu pukul 09.30 - 11.30 wib dan pukul 14.00 - 16.00 wib. Dalam kegiatan penjelajahan ini, anakanak dikenalkan dengan jenis-jenis flora khas dan fauna lokal, serta diajarkan cara menggunakan beberapa peralatan untuk pengamatan flora-fauna secara bergiliran. Peralatan yang digunakan seperti binokuler, kamera, insect net, alat serok ikan, dan kaca pembesar. Anak-anak peserta kegiatan ini tidak diajak untuk berkemah, karena rumah-rumah mereka berjarak kurang dari $2 \mathrm{~km}$ dari lokasi kegiatan.

b. Tahap Observasi Pemahaman Anak

Tahap observasi pemahaman anak dilaksanakan dalam rentang waktu 3 bulan, yaitu pada bulan Oktober - Desember 2019. Anak-anak yang telah diberikan pemahaman pelestarian flora-fauna dan lingkungan, diajak untuk berkomitmen melakukan hal-hal baik mengarah pada menjaga lingkungan. Tim pelaksana pengabdian mengunjungi kembali Taman Keanekaragaman Hayati Batu Putu sebanyak 2 kali kunjungan selama masa observasi, yaitu 17 November 2019 dan 1 Januari 2020. Kunjungan dimaksudkan untuk mengobservasi dan mencatat nilai-nilai yang berhasil diterapkan oleh anak dalam keseharian mereka. 
c. Tahap Evaluasi Kegiatan

Pada tahap ini diselenggarakan acara sederhana guna mengumpulkan kembali anak-anak peserta kegiatan sebelumnya. Acara dilaksanakan pada tanggal 23 februari 2020 di Aula Taman Keanekaragaman Hayati Batu Putu, dengan melibatkan guru Madrasah Ibtidaiyah (MI) Nurul Hikmah desa Batu Putu dan Pamong Desa.

\section{PEMBAHASAN}

Hasil yang dicapai dalam pelaksanaan kegiatan pengabdian di Taman Keanekaragaman Hayati Batu Putu, Desa Batu Putu, Teluk Betung Barat, Lampung adalah anak-anak mampu mengenali flora-fauna lokal di kawasan mereka (Tabel 1), dan memahami fungsi ekologis flora-fauna tersebut terhadap lingkungan. Pembentukan karakter peduli flora-fauna dan mau menjaga lingkungan muncul dari perilaku keseharian anak ketika bermain di sekitar taman kehati. Capaian-capaian berhasil diperoleh dari kegiatan pengabdian ini melalui aktifitas jelajah kawasan, bercerita dan bermain.

Tabel 1. Jenis-jenis flora dan fauna lokal yang dikenalkan kepada anak-anak

\begin{tabular}{cll}
\hline No & Jenis-jenis Flora & Jenis-jenis Fauna \\
\hline 1 & Bambu Hitam & Burung Cabak \\
2 & Bambu Kuning & Burung Gereja \\
3 & Bambu Rambat & Burung Elang \\
4 & Pohon Durian & Capung Air \\
5 & Pohon Kapuk & Ikan Kecil \\
6 & Pohon Kemiri & Kelelawar Gua \\
7 & Pohon Mangga & Kelelawar Codot \\
8 & Buah Maja & Kupu-kupu \\
9 & Pohon Petai hutan & Laba-laba air \\
10 & Pohon Jengkol & Siput sungai \\
\hline
\end{tabular}

\section{Pembelajaran Melalui Jelajah, Bercerita dan Bermain}

Kehidupan anak-anak adalah sarat dengan permainan. Mereka belajar melalui kegiatan bermain. Kegiatan mengenali flora-fauna dilakukan dengan menjelajahi kawasan dan bermain bersama anak, sembari bercerita tentang ragam flora-fauna lokal yang dijumpai (Gambar 1). Anak-anak memperoleh pengalaman belajar yang berbeda. Belajar mengenal flora-fauna menjadi mengasikkan, sebab mereka dapat mengamati langsung kehidupan di alam selayaknya seorang peneliti cilik atau anak petualang. 


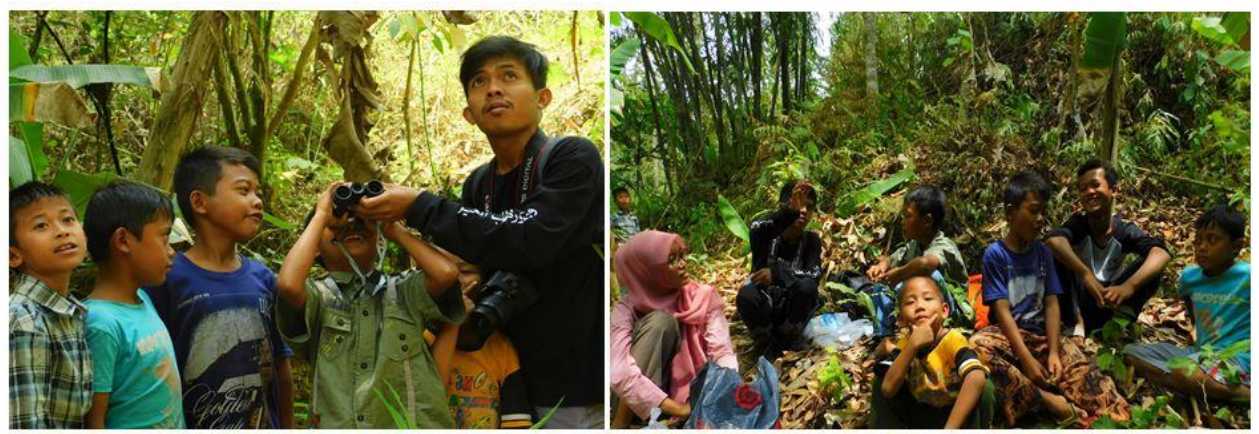

Gambar 1. Kegiatan mengenalkan flora-fauna pada anak-anak.

Anak-anak diajak mengamati burung dengan menggunakan binokuler, menangkap kupu-kupu dan serangga terbang dengan insect net untuk dipelajari kemudian dilepaskan kembali. Mereka bermain dan mengamati ikan-ikan juga biota air lainnya. Mereka juga mengamati aneka bunga dengan kaca pembesar dan kamera. Dengan memanfaatkan peralatan-peralatan sederhana yang biasa digunakan oleh peneliti di lapangan, rasa ingin tahu anak dapat dipuaskan dan proses belajar menjadi lebih optimal.

Pada waktu istirahat, anak-anak diajak duduk bercerita tentang peranan setiap flora dan fauna yang telah dijumpai bagi lingkungan taman kehati. Cerita ditekankan untuk menyugesti atau memberikan pemahaman anak mengenai pentingnya menjaga lingkungan taman kehati, sebagai salah satu kawasan hutan sekunder yang ada di tempat mereka bermukim. Tim pelaksana pengabdian berupaya menumbuhkan kecintaan anak terhadap flora-fauna yang ada di sekitar mereka melalui cerita. Berawal dari kecintaan anak terhadap flora-fauna ini, perlahan karakter peduli lingkungan dapat ditanamkan.

Penanaman karakter peduli lingkungan pada anak dapat dilakukan melalui media bercerita dan bermain. Menurut Lanti (2017), bermain adalah kegiatan yang mengasikkan bagi anak dan lewat bermain aspek-aspek perkembangan anak dapat ditingkatkan. Rentang usia dini hingga delapan tahun merupakan masa yang tepat untuk pendidikan karakter anak, dikarenakan kemampuan otak dalam hal menyerap nilai-nilai berkembang dengan baik dan menjadikan nilai-nilai tersebut dapat menjadi kebiasaan ketika dewasa (Polina, 2018). Dan menurut Yulianti, Rida, Dewanti, \& Diana (2014), menyatakan bahwa anakanak lebih mudah diajak untuk peduli lingkungan daripada orang dewasa.

\section{Observasi Pemahaman Anak}

Setelah kegiatan utama dilaksanakan, hasil yang tampak adalah anak-anak mampu memahami bahwa jenis-jenis flora dan fauna mempunyai manfaat bagi lingkungan mereka, dan penting untuk menjaga kelestariannya. Dalam dua kali kunjungan selama masa 
observasi, yaitu pada bulan November 2019 dan Januari 2020, tim pelaksana pengabdian mencatat bahwa anak-anak juga mampu berkomitmen melakukan hal-hal baik yang mengarah pada bentuk menjaga lingkungan. Suatu komitmen kecil yang sesuai porsi anakanak desa, seperti:

1) tidak membuang sampah plastik bungkus jajanan selama mereka bermain di dalam kawasan taman kehati;

2) tidak merusak jenis flora tertentu dan tidak pula menggangu kehidupan fauna yang telah mereka kenali;

3) tidak memburu fauna untuk dibunuh atau dijadikan permainan; dan

4) tidak bermain sendirian serta selalu berhati-hati saat bermain / berenang di sekitar air terjun.

Di luar kegiatan pengabdian, anak-anak di sekitar Taman Keanekaragaman Hayati Batu Putu terbiasa menjadikan kawasan ini sebagai ruang bermain. Mereka biasanya menyusuri jalan setapak dan menuruni tangga-tangga di dalam taman kehati untuk mencapai air terjun alami tempat mereka bermain, berenang dan menangkap ikan. Kini, mereka dapat bersikap bijak untuk cenderung memilih mengamati ikan-ikan daripada menangkapnya. Tim pelaksana pengabdian juga melihat keberhasilan pembentukan karakter anak ditunjukkan dengan sikap berani menegur pengunjung dewasa yang membuang sampah sembarangan, atau berperilaku merusak lingkungan taman kehati.

Karakter pada anak sesungguhnya dapat mudah dibentuk, tetapi upaya-upaya mengedukasi tentu membutuhkan waktu yang panjang, dan perlu dilakukan terus menerus. Zubaedi (2011), menyatakan bahwa terdapat 18 karakter yang perlu ditanamkan dalam diri anak, salah satunya adalah peduli lingkungan. Namun, pembelajaran karakter peduli lingkungan belum banyak diajarkan di sekolah formal, sehingga anak perlu mendapatkan tambahan pembelajaran informal.

Salah satu pembelajaran informal adalah ketika anak bermain dengan teman sebaya. Berteman dengan anak seumuran mempunyai peran dalam membentuk perilaku dan kepribadian anak, serta kemampuan berkomunikasi. Menurut Setiawati (2010), bermain dengan teman sebaya dapat meningkatkan interaksi sosial dengan baik. Pembelajaran informal juga termasuk pendidikan di lingkungan keluarga dan pendidikan yang ada di masyarakat, atau pendidikan yang diperoleh seseorang dari mengamati lingkungannya. Oleh karena itu, perhatian orang dewasa untuk membantu menanamkan karakter-karakter 
baik dan memberikan teladan bagi anak adalah sangat penting (Trenggonowati \& Kulsum, 2018).

\section{Evaluasi Kegiatan}

Acara terakhir dalam rangkaian kegiatan pengabdian ini, ditujukan untuk mengevaluasi kegiatan baik dari segi keberhasilan capaian, maupun kekurangan penyelenggaraan pengabdian atau membahas mengenai peluang kegiatan lanjutan agar karakter peduli lingkungan pada anak-anak di Desa Batu Putu terbangun dengan baik. Dalam acara sederhana yang melibatkan Guru Madrasah Ibtidaiyah (MI) Nurul Hikmah, sekolah formal terdekat dengan taman kehati, dan pamong desa setingkat RT maka susunan acara terdiri dari: registrasi peserta dan pembukaan, pre-test, susur flora, bermain puzzle fauna, post-test, tanya jawab dan pembagian hadiah, makan bersama dan penutupan.

Lembaran kuis (pre-test dan post-test) dibagikan kepada 30 anak. Tanya jawab dan diskusi terkait peningkatan perilaku kepedulian anak terhadap lingkungan dilakukan terutama bagi anak yang tidak dapat menjawab lembaran kuis, karena belum lancar membaca dan menulis. Peningkatan pengetahuan anak tentang flora dan fauna dapat terlihat dari penilaian kuis.

Kegiatan bermain puzzle dipilih sebagai media uji daya ingat anak terhadap florafauna yang sudah dikenalkan sebelumnya (Gambar 2). Selain itu, puzzle juga menjadi media untuk menanamkan pesan peduli lingkungan lewat gambar. Menurut Silmi \& Kusmarni (2017), permainan puzzle dapat menumbuhkan rasa keingintahuan anak. Permainan puzzle fauna dibuat oleh tim pelaksana pengabdian dari gambar-gambar digital yang diproduksi ketika kegiatan penjelajahan bersama anak. Sebagian besar anak-anak ternyata mampu mengingat flora-fauna yang telah mereka pelajari empat bulan sebelumnya, pada kegiatan tahap pertama. Mereka dapat menyebutkan jenis-jenis fauna lokal di kawasan Taman Keanekaragaman Hayati Batu Putu, seperti burung elang, burung cabak, kelelawar gua, kupu-kupu, ikan, kepiting dan siput sungai.

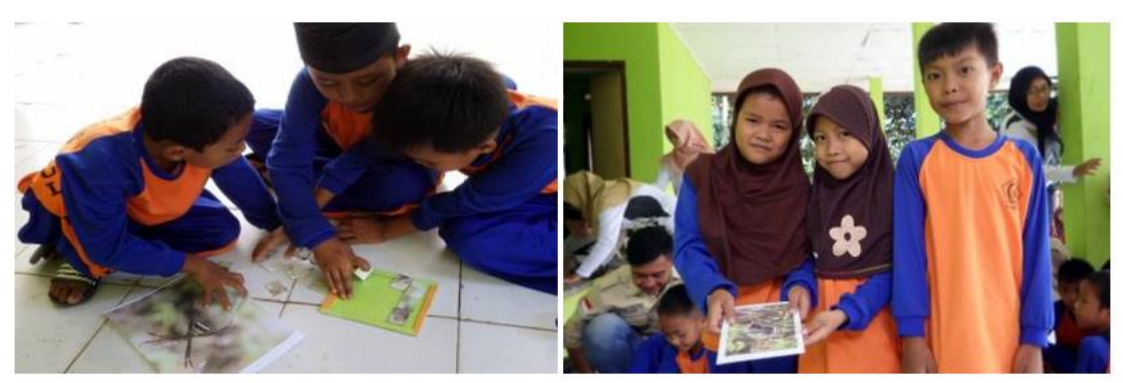

Gambar 2. Sekelompok anak asik menyusun puzzle flora -fauna. 
Anak-anak juga mengingat jenis-jenis flora unik dan langka yang terdapat di kawasan Taman Keanekaragaman Hayati Batu Putu, antara lain bambu, buah maja, durian, buah kemiri, pohon kapuk dan petai hutan. Sebagian anak kesulitan menyebutkan nama jenis-jenis flora, tetapi mampu menceritakan gambaran bentuk pohon dan fungsinya dengan bahasa khas mereka sendiri. Contohnya, anak-anak mengingat kemiri sebagai buah yang digunakan oleh anak lain (yang lebih besar) untuk membuat kumis palsu ketika mereka bermain, atau mereka memahami bahwa sebaiknya tidak menebang pohon agar ayah mereka tetap dapat memanen dan berjualan buah durian dari hutan.

Selama acara berlangsung, anak-anak diajak untuk membawa botol minum dari rumah, tidak membuang sampah sembarangan dan hemat penggunaan air cuci tangan. Pembelajaran-pembelajaran sederhana yang diharapkan dapat bermanfaat guna menumbuhkan kesadaran sejak dini untuk menjaga lingkungan taman Keanekaragaman Hayati Batu Putu khususnya, dan lingkungan umum di manapun anak-anak kelak berada.

Kekurangan pelaksanaan kegiatan pengabdian adalah bahwa tim pelaksana pengabdian kurang memaksimalkan penggunaan alat permainan edukatif bagi anak, seperti kartu flora-fauna, puzzle fauna, monopoli, dan atau lainnya. Apabila penggunakan alat permainan edukatif tersebut dimaksimalkan, maka luaran pengabdian dapat mengarah pada produk berpotensi paten.

\section{KESIMPULAN}

Dampak dan manfaat kegiatan pengabdian ini adalah anak-anak di sekitar Taman Keanekaragaman Hayati Batu Putu mampu mengenal beberapa flora khas dan fauna lokal di kawasan mereka, serta memahami peran ekologis flora-fauna tersebut terhadap lingkungan. Dari tingkat pemahaman itu, mulai pula terbentuk karakter peduli flora-fauna dan muncul sikap mau menjaga lingkungan yang tampak dari keseharian anak. Namun demikian, masih diperlukan upaya-upaya mendidik dan mengeristalkan karakter-karakter yang baik yang diperoleh agar tetap tertanam pada anak-anak hingga kelak mereka dewasa. Berdasarkan tingkat ketercapaian tujuan, maka kegiatan pengabdian ini dapat dikategorikan berhasil. Metode jelajah kawasan, bercerita dan bermain puzzle adalah cara menyenangkan yang sesuai untuk mengenalkan flora-fauna pada anak-anak di sekitar Taman Keanekaragaman Hayati Batu Putu. 


\section{UCAPAN TERIMA KASIH}

Ucapan terima kasih terutama ditujukan kepada pamong desa dan Kelurahan Batu Putu sebagai mitra dalam pengabdian ini. Ucapan terima kasih juga disampaikan kepada pihak-pihak yang membantu pelaksanaan kegiatan: Ibu Nurhayati, MI Nurul Hikmah Batu Putu; Bapak Haegel Alif atas karya foto yang digunakan menjadi Puzzle; dan mahasiswamahasiswa program studi Biologi Institut Teknologi Sumatera yang telah berpartisipasi menjadi relawan pendamping anak-anak selama kegiatan pengabdian.

\section{DAFTAR PUSTAKA}

Jayawardana, H. B. A. (2016). Pendidikan Karakter Peduli Lingkungan Sejak Dini Sebagai Upaya Mitigasi Bencana Ekologis. Prosiding Symbion (Symposium on Biology Education) Universitas Ahmad Dahlan, 49-64.

Lanti, E. (2017). Media Pengembangan Pendidikan Karakter Bagi Siswa Sekolah Dasar. Gorontalo: Athra Samudra.

Pemerintah Kota Bandar Lampung. (2019). Grand Design Pembangunan Pusat Wisata Edukasi Bambu di Taman Keanekaragaman Hayati Batu Putu.

Polina, L. (2018). Pembelajaran Karakter Melalui Media Dongeng pada PAUD Formal Binaan I Dan Binaan III Ciracas Jakarta Timur. Jurnal Solma, 7(2), 215-224. https://doi.org/http://dx.doi.org/10.29405/solma.v7i2.1665.

Setiawati, E. (2010). Interaksi Sosial dengan Teman Sebaya pada Anak Homeschooling dan Anak Sekolah Reguler. Jurnal Imiah Berkala Psikologi, 12(1), 55-65.

Silmi, M., \& Kusmarni, Y. (2017). Menumbuhkan karakter rasa ingin tahu siswa dalam pembelajaran sejarah melalui media puzzle. Factum, 6(2), 230-242.

Sulartiningrum, S., \& Nofiyanti, F. (2018). Pelatihan Peningkatan Kualitas SDM Bidang Pariwisata di Desa Wisata. Jurnal Solma, 7(2), 176-181. https://doi.org/http://dx.doi.org/10.29405/solma.v7i2.2228

Trenggonowati, D. L., \& Kulsum. (2018). Analisis Faktor Optimalisasi Golden Age Anak Usia Dini Studi Kasus di Kota Cilegon. Journal Industrial Servicess, 4(1), 48-56. https://doi.org/10.36055/jiss.v4i1.4088

Yulianti, D., Rida, Dewanti, H., \& Diana. (2014). Pengembangan karakter Peduli Lingkungan Anak Usia Dini Melalui Buku Cerita Bermuatan Sains Berwawasan Konservasi. Jurnal Penelitian Pendidikan, 31(1), 11-18.

Zubaedi. (2011). Desain Pendidikan Karakter: Konsepsi dan Aplikasinya dalam Lembaga Pendidikan. Jakarta: Kencana. 